\title{
INFLUÊNCIA DE PRÉ-TRATAMENTOS SOBRE A DESIDRATAÇÃO OSMÓTICA DE CARAMBOLAS
}

\author{
Elke SHIGEMATSU', Nenis Maria EIK', Mieko KIMURA', Maria Aparecida MAURO
}

\section{RESUMO}

A desidratação osmótica (DO) de fatias de carambola (Averrhoa carambola L.) em solução de sacarose foi estudada, com o objetivo de otimizar o processo. Num primeiro conjunto de experimentos, aplicou-se revestimento de coberturas comestiveis (pectina ou pectina+amido) sobre as fatias, seguido de $\mathrm{DO}$ em solução aquosa de sacarose (50\%, p/p, $27 \mathrm{C}$ ). Num segundo conjunto, foi realizada secagem parcial da cobertura, em estufa, antes da DO. Num terceiro conjunto de experimentos testou-se a adição de $\mathrm{CaCl}_{\text {, }}$ na solução osmótica. A aplicação dos revestimentos antes da DO não melhorou a eficiência (máxima perda água/ganho soluto) devido à grande retenção de umidade e à fácil impregnação de sacarose nos mesmos, enquanto que o tecido vegetal sem revestimento restringiu mais o ganho de soluto e propiciou maior saída de água. A utilização de $\mathrm{CaCl}_{2}$ a $0,04 \mathrm{M}$, na própria solução osmótica de sacarose, melhorou ligeiramente a eficiência do processo, em relação à solução sem o sal. A DO em solução de sacarose, sem e com a adição de $\mathrm{CaCl}_{2}$, geraram resultados positivos na qualidade sensorial da carambola em fatias, desidratadas em secador (60 e $70^{\circ} \mathrm{C}$ ), em comparação com a fruta não tratada, sendo que a melhor temperatura de secagem foi $60^{\circ} \mathrm{C}$.

Palavras-chave: cloreto de cálcio; coberturas comestiveis; avaliação sensorial; secagem; transferência de massa.

\section{SUMMARY}

PRE-TREATMENTS INFLUENCE ON THE OSMOTIC DEHYDRATION OF STAR FRUIT SLICES. Osmotic dehydration (OD) of star fruit (Averrhoa carambola L.) in sucrose solution was studied, aiming at optimizing the process. At a first set of trials, edible coating (pectin or pectin+starch) was applied on the slices followed by $\mathrm{OD}\left(50 \%, \mathrm{w} / \mathrm{w}, 27^{\circ} \mathrm{C}\right)$. On a second set of trials, the coatings partial drying in the oven, before OD, was also assessed. At a third set of trials, the addition of the $\mathrm{CaCl}$ in the osmotic solution itself was tested. The pectin based and pectin+starch based coatings, moist or oven-dried before the osmotic dehydration, were not viable on the process efficiency improvement (maximum water loss/solute gain) due to the high moisture retention and the easy sucrose impregnation of them. The vegetal tissue, uncoated, restrained more of the solute transfer and allowed a higher water

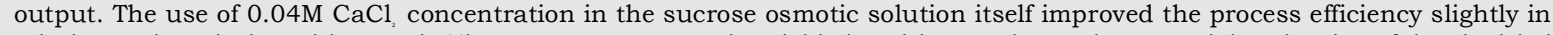
relation to the solution without salt. These pre-treatments also yielded positive results on the sensorial evaluation of the air-dried $(60$ and $70 \mathrm{C})$ star fruit slices, in comparison with the non-treated fruit, and the best temperature was $60^{\circ} \mathrm{C}$

Keywords: calcium chloride; edible coatings; sensory analysis; drying; mass transfer.

\section{1 - INTRODUÇÃO}

A carambola (Averrhoa carambola L.), fruta de origem Asiática, é cultivada no Brasil com grande êxito, pois a planta necessita de climas quentes e úmidos. As carambolas são classificadas em dois grandes grupos, o tipo ácido e o tipo doce [1]. A caramboleira possui grande potencial devido à capacidade de rápido desenvolvimento, alta produtividade, seleção de novos tipos doces e fruto com aparência e sabor únicos [24 apud 1]. A produção ocorre o ano todo, principalmente nos meses de fevereiro e março [23]. Essa fruta, considerada exótica, é fonte de vitaminas, sais minerais e fibras, compostos essenciais para a nutrição dos seres humanos [20, 25]. Por outro lado, devido a sua fragilidade e alto teor de umidade, que facilitam sua deterioração, a carambola necessita de muitos cuidados na colheita, transporte e armazenamento, $\mathrm{e}$ apresenta vida-de-prateleira curta, mesmo em condições de temperatura e umidade controladas.

\footnotetext{
Recebido para publicação em 08/09/2004. Aceito para publicação em 25/07/2005 (001402).

'Departamento de Engenharia e Tecnologia de Alimentos, Instituto de Biociências, Letras e Ciências Exatas (IBILCE), Universidade Estadual Paulista (UNESP). Endereço: Rua Cristovão Colombo, 2265, CEP: 15054-000, São José do Rio Preto-SP. E-mail: cidam@ibilce.unesp.br

A quem a correspondência deve ser enviada.
}

A secagem ou desidratação é muito utilizada para a preservação de alimentos, pois, além de diminuir a disponibilidade da água para reações de deterioração dos produtos, aumentando a estabilidade dos mesmos, e reduzir seu volume, facilitando o transporte e armazenagem, trata-se de uma técnica simples, muitas vezes menos dispendiosa que outros processamentos. A secagem de alimentos utilizando o ar aquecido baseia-se no aumento da temperatura do produto para evaporação da água e, se não for bem controlada, pode provocar alterações indesejáveis na aparência, cor, textura, bem como no conteúdo de nutrientes do produto final.

A desidratação osmótica (DO) de vegetais por imersão em soluções hipertônicas surgiu como processo alternativo para redução da atividade de água dos mesmos, minimizando os prejuízos da qualidade nutricional e sensorial. Devido às características das membranas da célula vegetal, que são permeáveis à água e impermeáveis a solutos de alto peso molecular, como a sacarose [5], geralmente ocorre maior transferência de água do vegetal para a solução do que transferência de soluto da solução para o primeiro. As células vegetais são envolvidas por uma parede celulósica, que proporciona firmeza aos tecidos, mas que não se apresenta como barreira principal à transferência de substâncias, porque contém numerosos interstícios relativamente grandes [18]. O conteúdo celular, conhecido como protoplasto, é separado da parede celular pelo plasmalema (membrana plasmática). 
Sob condições normais, a pressão interna da célula empurra o plasmalema firmemente contra a parede celular. O tecido vegetal, em equilíbrio com a água pura, apresenta máxima turgidez. Se for adicionado, à água, um soluto como a sacarose, conforme a concentração for aumentada, a pressão hidrostática dentro da célula diminuirá devido ao fluxo de água para fora da mesma, e ela irá encolher até perder a turgidez, atingindo o ponto chamado de plasmólise incipiente [18]. A partir daí, aumentando-se a concentração de soluto, haverá um fluxo de água para fora da célula e um fluxo de soluto no sentido contrário. A célula irá plasmolisar, isto é, ocorrerá a separação do protoplasto da parede celular e se formará um espaço ocupado pela solução osmótica.

A DO, sozinha, não é capaz de reduzir a atividade de água de um alimento a niveis suficientemente baixos que garantam sua estabilidade [27]. Em geral, a DO elimina ao redor de $50 \%$ da massa inicial do vegetal devido à redução da umidade. A perda de água ocorre, principalmente, durante as duas primeiras horas e o maior ganho de sólidos, durante os 30 minutos iniciais [11]. A impregnação de solutos pode ser desejável, como é o caso de frutas com elevada acidez, cujo tratamento em soluções de açúcar torna o sabor mais agradável [28]. No entanto, excessiva incorporação de solutos pode ser inconveniente nesses processos. Alguns estudos fazem uso da combinação de coberturas comestiveis com DO, com o intuito de minimizar a transferência de solutos da solução para o produto e maximizar a perda de água $[8,9,13]$. Filmes e coberturas comestíveis são finas camadas de material digerivel adicionadas sobre um alimento, que têm aplicação bastante ampla, podendo ser utilizados como barreiras à umidade, ao oxigênio, a solutos, a compostos voláteis, e ainda atuar como veículo para agentes conservantes, como suporte para a melhoria da integridade estrutural do alimento, dentre outros [10]. CAMIRAND et al. [9] testaram diversas coberturas (amido de milho e de batata, alginato de sódio, polipectinato de sódio, pectina, metil e etil celulose e maltodextrina) medindo a transferência de água e a transferência de soluto (glicerol, sacarose e dextrose) através dos filmes, em uma célula de difusão. Os tratamentos mais eficientes para a sacarose corresponderam ao filme de amido de milho e ao filme composto por pectina e amido de milho. Porém, a combinação das coberturas com os diferentes tecidos vegetais, pode levar a resultados diversos daqueles obtidos na célula de difusão, para a cobertura sozinha. OGONEK \& LENARD [19] obtiveram diminuição tanto da perda de água quanto do ganho de solutos, desidratando osmoticamente morangos cobertos com pectina, amido de batata ou uma mistura dos dois componentes.

Os trabalhos de LENART \& PIOTROWISKI [15], assim como de LENART \& DABROWSKA [14], abordam a formação de coberturas em tecidos vegetais antes da desidratação osmótica. Os autores aplicaram a tecnologia a pedaços de maçãs e compararam o desempenho de algumas misturas à base de amido e pectina. A eficiência do processo durante a desidratação osmótica, em algumas condições de tratamento, foi notavelmente aumentada com a presença da cobertura nos pedaços de fruta, principalmente quando as temperaturas de DO eram elevadas.

AZEREDO \& JARDINE [2] também obtiveram sucesso utilizando métodos combinados, tendo como resultado produtos similares à fruta fresca. Os autores constataram que coberturas de pectina de baixa metoxilação e alginato, aplicadas em pedaços de abacaxi previamente branqueados, aumentaram significativamente a eficiência da desidratação osmótica.

Outras técnicas também têm se mostrado viáveis na melhoria da eficiência do processo assim como na incorporação de nutrientes. HENG, GUILBERT \& CUQ [12], estudando desidratação osmótica de mamão em soluções de açúcares, observaram que a adição de cloreto de cálcio na solução aumentou a eficiência do processo, sendo que a concentração ótima foi $0,03 \mathrm{M}$ (em íon cálcio). O cálcio, que difunde no tecido, associa-se à pectina parcialmente solubilizada das paredes celulares da fruta, firmando a estrutura e ao mesmo tempo criando uma barreira à difusão do soluto. BARRERA, BETORET \& FITO [4] enriqueceram amostras de maçã com íons Ca e Fe, adicionando-os à solução osmótica de sacarose, sendo que os mesmos não afetaram significativamente a cinética da DO.

Além da avaliação da eficiência em função das condições de processo, a qualidade sensorial dos produtos finais também deve ser avaliada com relação aos seus atributos principais, como aparência, sabor e textura. Incrementos na qualidade sensorial de produtos desidratados, mediante a utilização de processos combinados, já vêm sendo reportados na literatura [7, 17].

Os objetivos do presente trabalho foram: avaliar a influência da aplicação de coberturas comestiveis (pectina e pectina+amido) e da adição de cálcio à solução osmótica, sobre a eficiência (maior perda de água/ganho de soluto) da DO de carambolas em fatias, e comparar a qualidade sensorial de fatias submetidas ao tratamento mais eficiente com fatias tratadas osmoticamente em solução de sacarose e não tratadas, secas a $60^{\circ} \mathrm{C} \mathrm{e} 70^{\circ} \mathrm{C}$.

\section{2 - MATERIAL E MÉTODOS}

\section{1 - Material}

Carambolas (Averrhoa carambola L.), tipo doce, ligeiramente maduras, foram adquiridas no mercado local CEAGESP (São José do Rio Preto, SP) e armazenadas em geladeira a $5^{\circ} \mathrm{C}$, em embalagens de filme plástico, por até 3 semanas. O agente osmótico utilizado foi sacarose comercial e os íons cálcio foram provenientes de cloreto de cálcio hidratado (grau comestivel USP). Os polissacarídeos utilizados para formação de coberturas foram: pectina de baixa metoxilação (Grindsted Pectin LA 210) e amido solúvel (Synth); todos os reagentes tinham grau de pureza P.A. 


\section{2 - Metodologia experimental}

\subsection{1 - Amostragem e preparo de amostras}

Selecionaram-se carambolas com cor e tamanho semelhantes, não totalmente maduras. As frutas foram lavadas e cortadas no sentindo transversal, em um cortador elétrico de frios da Marca Eco, regulado para espessura em torno de $4,50 \mathrm{~mm}$. As fatias foram colocadas em saco plástico e misturadas, e amostras representativas foram retiradas aleatoriamente.

\subsection{2 - Adição de coberturas}

Utilizaram-se quatro tipos de coberturas formadas a partir de soluções aquosas contendo $1 \%$ de pectina, $2 \%$ de pectina, $3 \%$ de pectina e $1 \%$ de pectina com $2 \%$ de amido. As soluções foram preparadas mediante aquecimento e agitação constante, e a seguir, resfriadas à temperatura ambiente.

Pesavam-se 80 a 100 gramas de fatias de carambola, sendo que cinco fatias eram dispostas, por vez, num cesto construído em tela de nylon, de $15 \times 15 \mathrm{~cm}$ com espaçamento de $2 \mathrm{~cm}$ entre os fios, para garantir uma grande área vazada. Esse cesto era mergulhado por 60 segundos num recipiente retangular $(20 \times 20 \mathrm{~cm})$ contendo a solução formadora de cobertura. A seguir o mesmo cesto era mergulhado por 30 segundos na solução de cloreto de cálcio a $2 \%$, gelificando a pectina e formando uma camada firme na superficie das fatias. Realizava-se, então, um enxágüe, em água destilada, por 10 segundos, as amostras eram colocadas em bandejas para a água escorrer, e por fim eram delicadamente enxugadas com papel absorvente e pesadas.

Num diferente ensaio, as amostras com cobertura de pectina, com $2 \%$ de concentração, foram secas dentro de estufas com recirculação de ar, após serem distribuídas sobre telas metálicas apoiadas em suportes. Os tempos e as temperaturas testados foram 40 minutos $/ 40^{\circ} \mathrm{C}, 10 \mathrm{mi}-$ nutos $/ 70^{\circ} \mathrm{C}$ e 40 minutos $/ 70^{\circ} \mathrm{C}$.

Ensaios independentes foram realizados para estimar a umidade das coberturas. Para tanto, após a formação das mesmas, elas foram retiradas com espátula e pinça e tiveram seu teor de sólidos totais determinado.

\subsection{3 - Procedimento para seleção de tratamento}

Para selecionar o melhor tratamento, foram realizados três conjuntos de experimentos:

- Conjunto I: Fatias revestidas com coberturas e desidratadas osmoticamente em solução aquosa de sacarose $(50 \%, \mathrm{p} / \mathrm{p})$ em cuba, por $2 \mathrm{~h}$ (CB-DO), a $27^{\circ} \mathrm{C}$, sob agitação de 700rpm. Utilizaram-se quatro tipos de coberturas formadas a partir de soluções aquosas contendo $1 \%$ de pectina, $2 \%$ de pectina, $3 \%$ de pectina e $1 \%$ de pectina com $2 \%$ de amido.

- Conjunto II: Fatias revestidas com coberturas contendo $2 \%$ de pectina, foram submetidas a uma rápida secagem em estufa $\left(40\right.$ minutos $/ 40^{\circ} \mathrm{C}, 10$ minutos $/ 70^{\circ} \mathrm{C}$ e
40 minutos $/ 70^{\circ} \mathrm{C}$ ) e desidratadas osmoticamente em solução de sacarose $(50 \%, \mathrm{p} / \mathrm{p})$ em cuba, por $2 \mathrm{~h}$ (CB-SDO), a $27^{\circ} \mathrm{C}$, sob agitação de 500rpm.

- Conjunto III: Fatias sem cobertura (in natura) desidratadas osmoticamente em solução de sacarose (50\%, $\mathrm{p} / \mathrm{p})$ com adição de cloreto de cálcio $(0,02 \mathrm{M}, 0,04 \mathrm{M}$, $0,06 \mathrm{M})$, em plataforma de agitação, por $2 \mathrm{~h}$ (DO-Ca), a $27^{\circ} \mathrm{C}$, sob agitação de $150 \mathrm{rpm}$.

Todos os ensaios tiveram amostras sem cobertura desidratadas em solução de sacarose a 50\%, p/p, como controle (DO).

\subsection{4 - Processamento}

- Desidratação osmótica em cuba

Esse processamento corresponde aos Conjuntos I e II de experimentos.

Amostras de fatias com ou sem cobertura, de aproximadamente $100 \mathrm{~g}$, foram pesadas em cestos construídos em nylon. Cada cesto tinha uma repartição no meio, de forma a separar melhor as fatias.

Os cestos foram dispostos no equipamento de desidratação osmótica que consiste de uma cuba quadrada construída em aço inoxidável, de dimensões: $30 \times 30 \times 35 \mathrm{~cm}$. A cuba comporta 4 cestos de cada vez, que se encaixam numa estrutura. A agitação da solução foi conduzida por um agitador mecânico (Fisatom, modelo 723, potência de $350 \mathrm{~W})$ com hélice naval (10cm de diâmetro), empregando-se altas velocidades. A temperatura da solução foi mantida em $27^{\circ} \mathrm{C}$ através de água circulando numa camisa externa à cuba, proveniente de um banho termostático que dispõe de refrigeração.

Após 2 horas de processo, as amostras foram retiradas do banho osmótico, rapidamente enxagüadas e colocadas em bandejas, e a seguir secas com material absorvente. As fatias foram então pesadas, desintegradas e homogeneizadas. Sólidos totais foram determinados em todas as amostras. Açúcares totais e redutores foram analisados nas amostras in natura.

- Desidratação osmótica em plataforma de agitação (shaker)

Com o intuito de realizar diversos ensaios simultaneamente para o Conjunto III de experimentos, utilizouse uma incubadora refrigerada com plataforma de agitação orbital, dispondo de temperatura e velocidade de agitação controladas (Marconi, modelo MA 830/A). Na plataforma encaixavam-se recipientes cilíndricos de vidro, de $800 \mathrm{~mL}$, com tampa, contendo $800 \mathrm{~g}$ de solução aquosa de sacarose a $50 \%$, p/p. Em cada recipiente foram desidratadas aproximadamente $50 \mathrm{~g}$ de fruta fresca, o que garantiu uma relação alta entre solução: fruta. Para cada concentração de $\mathrm{CaCl}_{2}$ foram preparados dois recipientes de solução osmótica.

Após 2 horas de processo a temperatura de $27^{\circ} \mathrm{C}$, as fatias foram retiradas, limpas com pano úmido e secas com material absorvente. Foram então pesadas, desinte- 
gradas e homogeneizadas. Sólidos totais e açúcares totais e redutores foram analisados em todas as amostras.

\section{- Secagem}

Fatias de carambolas, sem tratamento e prétratadas em solução de sacarose (sem e com adição de $\left.\mathrm{CaCl}_{2} 0,04 \mathrm{M}\right)$, foram secas a 60 e $70^{\circ} \mathrm{C}$, em secador com fluxo de ar aquecido $(2 \mathrm{~m} / \mathrm{s})$ paralelo às amostras, dispostas em três bandejas construídas em tela metálica, por 5 horas, tempo suficiente para a obtenção de peso constante. Sólidos totais e densidade foram determinados antes e depois de cada secagem. As amostras obtidas foram seladas a vácuo em sacos de polietileno, até a realização de análise sensorial.

\section{3 - Métodos analíticos}

Para a determinação de açúcares totais e redutores, a metodologia adotada foi a titulação de óxido-redução [29], utilizando-se aproximadamente 10-20 gramas da amostra.

Os sólidos totais foram determinados utilizando-se o método gravimétrico, no qual amostras trituradas de aproximadamente 2 gramas, em triplicata, foram pesadas em frascos pesa-filtro e secas em estufa a vácuo, a $60^{\circ} \mathrm{C}$, até peso constante.

\section{4 - Análise sensorial}

As carambolas em fatias obtidas na secagem foram servidas em pires de porcelana codificados com números aleatórios de 3 dígitos, e avaliadas por uma equipe de 35 provadores não treinados, em cabines individuais, quanto aos atributos aparência, sabor e textura, utilizando uma escala de qualidade de onze pontos com notas variando de 0 a 10 . A opção por nota numérica ao invés de termos descritivos (desgostei muitíssimo e gostei muitíssimo) foi por entender que os provadores não treinados teriam maior facilidade de aplicá-la. As seis amostras foram apresentadas simultaneamente, e em ordens distintas, para cada provador.

\section{5 - Forma de análise dos resultados}

A eficiência da DO foi calculada, para cada tratamento (item 2.2.3.), com base na perda de água e ganho de sacarose, determinados por meio do levantamento de dados experimentais de massas, teores de sólidos totais e, em alguns casos, açúcares totais e redutores.

A variação de massa em relação à massa inicial é representada segundo

$$
\Delta M=\frac{M_{t}-M_{i}}{M_{i}}=\Delta P_{\text {ag } u a}+\Delta G_{\text {sólidos }}
$$

$\operatorname{com} M_{s}$ representando a massa final (após a desidratação osmótica) e $M_{i}$, a massa inicial, antes da DO, isto é, das fatias sem cobertura (tratamentos de DO e DO-Ca), das fatias com cobertura (tratamentos CB-DO) e das fatias com coberturas adicionadas e parcialmente secas em estufa (tratamentos CB-S-DO).
A perda de água em relação à massa inicial, $\left(\Delta P_{a, \ldots a}\right)$, é calculada segundo:

$\Delta P_{\text {agua }}=\frac{\left\lfloor\left(M_{f} U_{f}\right)-\left(M_{i} U_{i}\right)\right\rfloor}{M_{i}}$

com $U$, representando o teor de umidade da fruta após a desidratação osmótica e $U$, o teor de umidade inicial antes da DO.

O ganho de sólidos em relação à massa inicial

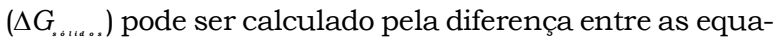
ções (1) e (2), isto é:

$\Delta G_{\text {sólidos }}=\frac{\Delta M}{M_{i}}-\Delta P_{\text {agua }}$

ou ainda, com base nos teores de sacarose determinados experimentalmente. Neste caso o ganho de soluto é descrito em função do teor inicial e final de sacarose, e representado pelo ganho de sacarose em relação à massa ini$\operatorname{cial}\left(\Delta G_{\text {. . ....... })}\right)$ segundo:

$\Delta G_{\text {sacarose }}=\frac{\left\lfloor\left(M_{f} S_{f}\right)-\left(M_{i} S_{i}\right)\right\rfloor}{M_{i}}$

onde $S_{\imath}$ representa o teor de sacarose inicial e $S_{f}$ o teor de sacarose determinado nas amostras, após a DO.

Negligenciando-se qualquer perda de sólidos da fruta para solução, o teor de sacarose pode ser calculado segundo:

$S_{f}=\frac{\left[\left(\Delta G_{\text {sólidos }} M_{i}\right)+\left(M_{i} S_{i}\right)\right]}{M_{f}}$

A perda de açúcares redutores em relação à massa inicial $\left(\Delta P_{\text {a ...... }}\right)$ é calculada mediante seus teores, medidos experimentalmente:

$\Delta P_{\text {ac.red. }}=\frac{\left\lfloor\left(M_{t} A R_{f}\right)-\left(M_{i} A R_{i}\right)\right\rfloor}{M_{i}}$

onde $A R_{i}$ representa o teor inicial de açúcares redutores e $A R$ o teor final de açúcares redutores determinado nas amostras, após a DO.

A eficiência $(E)$ é medida pela relação entre perda de água e ganho de sólidos (sacarose), durante o processo de DO:

$E=\Delta P_{\text {agua }} / \Delta G_{\text {sacarose }}$

\section{3 - RESULTADOS E DISCUSSÃO}

\section{1 - Comparação entre coberturas úmidas - Conjunto I}

Fatias revestidas com pectina ou pectina+amido e fatias sem cobertura foram desidratadas osmoticamente 
em cuba contendo $15 \mathrm{~kg}$ de solução aquosa de sacarose, durante 2 horas. A espessura média das amostras foi $4,5 \mathrm{~mm}$. O teor final de umidade, a variação total de massa (equação 1), a perda de água (equação 2) e o ganho de sólidos (equação 3), os três últimos em relação à massa inicial que foi imersa na solução osmótica, e a eficiência (equação 7), são apresentados na Tabela 1.

TABELA 1 - Teor de umidade $\left(U_{t}\right)$, variação de massa $(\Delta M)$, perda de água $\left(\Delta P_{\text {.... }}\right)$, ganho de sólidos $\left(\Delta G_{\text {....... }}\right)$ e eficiência $(E)$, na DO de fatias de carambola revestidas com pectina, pectina+amido, e sem cobertura

\begin{tabular}{cccccc}
\hline Coberturas & $U,(\%, \mathrm{bu})$ & $\Delta M(\%)$ & $\Delta P_{\text {dgena }}(\%)$ & $\Delta G_{\text {sóihisa }}(\%)$ & $E$ \\
\hline Pectina(1\%) & $73,36 \pm 0,06$ & $-42,42$ & $-49,73$ & 7,31 & $-6,80$ \\
Pectina(2\%) & $77,16 \pm 0,13$ & $-42,65$ & $-47,81$ & 5,16 & $-9,27$ \\
Pectina(3\%) & $72,91 \pm 0,03$ & $-44,67$ & $-52,01$ & 7,34 & $-7,09$ \\
Pectina(1\%)-Amido(2\%) & $75,55 \pm 0,11$ & $-45,52$ & $-50,99$ & 5,47 & $-9,32$ \\
Sem cobertura & $71,96 \pm 0,05$ & $-55,40$ & $-59,74$ & 4,34 & $-13,76$ \\
\hline \\
Teores médios (base úmida) na carambola in natura: água 91,70\%; açúcar redutor 5,37\%; \\
sacarose 0\%.
\end{tabular}

Pela Tabela 1 constata-se que o tratamento mais eficiente corres ponde à amostra sem cobertura. A aplicação dos revestimentos reduziu a perda de água do conjunto fruta-cobertura, mas não restringiu a entrada de solutos, o que abaixou muito a eficiência do processo.

Um ensaio independente também foi conduzido para determinar o conteúdo de umidade nas coberturas, após a aplicação e gelificação. A massa de cobertura adicionada à fruta $\left(M_{c}\right)$, em relação à massa total do conjunto fruta/cobertura $\left(M_{t /}\right)$, assim como o teor de umidade dessas coberturas $\left(U_{\text {. }}\right)$ e do conjunto $\left(U_{r /}\right)$, são apresentados na Tabela 2. Pode-se observar que, quanto maior a porcentagem de pectina na cobertura, mais massa é incorporada às fatias. Por outro lado, o conteúdo de umidade das coberturas é alto, o que explica a maior variação de água da amostra com cobertura preparada com solução de 3\% de pectina (Tabela 1).

TABELA 2 - Fração de massa de cobertura $\left(M_{c} / M_{f / c}\right)$, teor de umidade das coberturas ( $U_{c}$ ) e do conjunto fatia/cobertura $\left(U_{t / \mathrm{e}}\right)$

\begin{tabular}{cccc}
\hline Cobertura & $M_{c} / M_{f / c}(\%)$ & $U_{c}(\%, \mathrm{bu})$ & $U_{f / c}(\%, \mathrm{bu})$ \\
\hline Pectina(1\%) & 2,48 & $97,18 \pm 0,35$ & $91,97 \pm 0,14$ \\
Pectina(2\%) & 6,99 & $95,02 \pm 0,22$ & $92,06 \pm 0,11$ \\
Pectina(3\%) & 13,63 & $95,60 \pm 0,11$ & $92,35 \pm 0,35$ \\
Pectina(1\%)-Amido(2\%) & 6,51 & $96,75 \pm 0,25$ & $92,16 \pm 0,25$ \\
\hline Teores médios (base úmida) na carambola in natura: água $91,70 \%$; açúcar redutor 5,37\%; \\
sacarose 0\%.
\end{tabular}

O teor de sacarose final (equação 5) foi calculado a

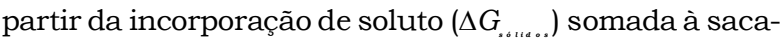
rose inicial. Os valores são apresentados na Tabela 3 , em base úmida e em base seca. Estes últimos mostram a porcentagem de sacarose sobre os sólidos totais finais do produto.
TABELA 3 - Teor de sacarose $(S)$ calculado após a DO de fatias de carambola revestidas com pectina ou pectina+amido, e sem cobertura

\begin{tabular}{ccc}
\hline Cobertura & $S_{,}(\%, \mathrm{bu})$ & $S_{,}(\%, \mathrm{bs})$ \\
\hline Pectina(1\%) & 12,69 & 47,64 \\
Pectina(2\%) & 8,99 & 39,36 \\
Pectina(3\%) & 13,26 & 48,95 \\
Pectina(1\%)- & & \\
Amido(2\%) & 10,05 & 41,10 \\
Sem cobertura & 9,73 & 34,70 \\
\hline Teores médios (base úmida) na carambola in natura: água $91,70 \% ;$ açúcar redutor $5,37 \% ;$
\end{tabular}
sacarose $0 \%$

A cobertura elevou o teor de água do conjunto fatia/cobertura desidratado osmoticamente (Tabela 2). Além disso, os resultados indicam que a sacarose difundiu com facilidade nessas camadas de pectina ou pectina+amido, impregnando muito o produto final com açúcar (Tabela 3). Conseqüentemente, a eficiência diminuiu em relação às fatias sem revestimento (Tabela 1).

\section{2 - Comparação entre coberturas parcialmen- te secas - Conjunto II}

Neste ensaio, seguindo procedimento utilizado por LENART \& PIOTROWSKI [15], as fatias de carambola foram revestidas com a cobertura de $2 \%$ de pectina e levadas à estufa de recirculação de ar para uma secagem parcial. A seguir foram desidratadas osmoticamente em $15 \mathrm{~kg}$ de solução a $50 \%(\mathrm{p} / \mathrm{p})$, durante 2 horas. O controle foi realizado com fatias de carambola sem cobertura, levadas diretamente ao banho osmótico. Neste ensaio a espessura média das amostras foi igual a 4,3mm.

$\mathrm{Na}$ Tabela 4 são apresentados os resultados de teor de umidade, variação total de massa (equação 1), perda de água (equação 2) e ganho de sólidos (equação 3), os três últimos em relação à massa inicial que foi imersa na solução osmótica, e a eficiência (equação 7).

TABELA 4 - Teor de umidade $\left(U_{f}\right)$, variação de massa $(\Delta M)$, perda de água $(\Delta P \quad)$, ganho de sólidos $(\Delta G \quad)$ e eficiência $(E)$, na DO de fatias de carambola revestidas com pectina $(2 \%)$ e secas em estufa em diferentes condições, e sem cobertura

\begin{tabular}{|c|c|c|c|c|c|}
\hline Cobertura/Secagem & $U,(\%, \mathrm{bu})$ & $\Delta M(\%)$ & $\Delta P_{\text {digua }}(\%)$ & $\Delta G_{\text {suldar }}(\%)$ & $E$ \\
\hline Pect $(2 \%)-40 n$ & $80,16 \pm 0,06$ & $-30,81$ & $-35,86$ & 5,05 & $-7,10$ \\
\hline Pect $(2 \%)$ - & 80,20 & $-31,52$ & $-37,39$ & 5,87 & $-6,37$ \\
\hline Pect $(2 \%)-40 \mathrm{~min} / 7$ & $78,43 \pm$ & $-32,76$ & $-38,86$ &, 10 & $-6,37$ \\
\hline Sem cobertura & $77,39 \pm 0,20$ & $-44,53$ & $-48,51$ & 3,98 & $-12,17$ \\
\hline
\end{tabular}

$4,80 \%$; sacarose $0,05 \%$

Esse ensaio não é comparável ao anterior, devido à diferente agitação no sistema. O efeito da resistência externa provavelmente interferiu na transferência de massa, o que se conclui pelo teor de umidade da amostra sem cobertura, após a desidratação osmótica, que resultou superior ao do primeiro ensaio (Tabela 1). Embora os teores de umidade de todas amostras desidratadas osmoticamente tenham sido semelhantes, a maior eficiência, mais uma vez, foi obtida na DO da amostra sem cobertura. 
Também foi determinado experimentalmente o teor de umidade das coberturas $\left(U_{c}\right)$ após a aplicação e gelificação, assim como do conjunto fatia/cobertura $\left(U_{\mu /}\right)$, após a secagem na estufa (Tabela 5).

TABELA 5 - Teor de umidade das coberturas $\left(U_{\text {, }}\right.$ ) e do conjunto fatia/cobertura $\left(U_{t / t}\right)$ secos em estufa em diferentes condições

\begin{tabular}{|c|c|c|}
\hline Cobertura/Secagem & $\begin{array}{c}U_{c} \\
(\%, b u)\end{array}$ & $\begin{array}{c}U_{f / c} \\
(\%, b u)\end{array}$ \\
\hline Pect $(2 \%)-40 \mathrm{~min} / 40^{\circ} \mathrm{C}$ & & $91,32 \pm 0,06$ \\
\hline Pect $(2 \%)-10 \min / 70^{\circ} \mathrm{C}$ & $95,21 \pm 0,14$ & $92,31 \pm 0,11$ \\
\hline Pect $(2 \%)-40 \mathrm{~min} / 70^{\circ} \mathrm{C}$ & & $91,60 \pm 0,19$ \\
\hline
\end{tabular}

Na Tabela 6 são apresentados os teores de sacarose calculados nas fatias processadas, em base úmida e seca.

TABELA 6 - Teor de sacarose $\left(S_{f}\right)$ calculado após a DO de fatias de carambola revestidas com pectina $(2 \%)$ e secas em estufa em diferentes condições, e sem cobertura

\begin{tabular}{ccc}
\hline Cobertura/Secagem & $\begin{array}{c}S_{f} \\
(\%, b u)\end{array}$ & $\begin{array}{c}S_{f} \\
(\%, b s)\end{array}$ \\
\hline Pect $(2 \%)-40 \mathrm{~min} / 40^{\circ} \mathrm{C}$ & 7,30 & 36,79 \\
Pect $(2 \%)-10 \mathrm{~min} / 70^{\circ} \mathrm{C}$ & 8,57 & 43,28 \\
Pect $(2 \%)-40 \mathrm{~min} / 70^{\circ} \mathrm{C}$ & 9,08 & 42,10 \\
Sem cobertura & 7,19 & 31,80 \\
\hline Teores médios (base úmida) na carambola in natura: água $91,44 \%$; açúcar redutor $4,80 \% ;$ \\
sacarose $0,05 \%$.
\end{tabular}
sacarose $0,05 \%$

A maior temperatura na estufa propiciou maior impregnação de sacarose nas fatias com revestimento ( $\mathrm{Ta}$ bela 6 , teores em base seca). É possivel que a temperatura mais elevada tenha injuriado o tecido vegetal abaixo da cobertura, facilitando a difusão da sacarose no mesmo.

Todo o conjunto de resultados mostra que o processo mais eficiente sempre foi aquele com as fatias de carambola sem cobertura. A explicação mais plausivel é que a cobertura aumenta a resistência, reduzindo a transferência de água e a transferência de sacarose no tecido da fruta. A própria cobertura fica muito impregnada de sacarose, além de reter considerável quantidade de água na sua preparação. Esta água não é facilmente eliminada durante a secagem da cobertura na estufa, o que se observa pelo teor de umidade das coberturas úmidas e das frutas com cobertura, reportados na Tabela 5.

Por outro lado, o tecido vegetal, enquanto mantém suas estruturas celulares integras, restringe a transferência de soluto, pois moléculas grandes não são capazes de atravessar as membranas celulares. Sendo assim, enquanto a membrana plasmática que envolve o protoplasto estiver intacta, a sacarose não atravessará a mesma, e se restringirá aos espaços intersticiais e aos espaços de plasmólise. No entanto, quando a solução tem concentração elevada, a temperatura é alta ou os tempos de imersão são muito longos, as estruturas celulares podem ser injuriadas e o soluto passa a ocupar todos os espaços da célula.
Esse pode ser um dos motivos de haver tanta contradição entre resultados obtidos na desidratação osmótica de frutas com coberturas. No presente trabalho a concentração utilizada é moderada (50\%), o tempo de exposição não é longo (2h) e a temperatura é ambiente $(27 \mathrm{C})$. Nessas condições o tecido celular mostrou-se muito mais seletivo do que a cobertura adicionada sobre o mesmo. Os resultados aqui obtidos poderiam ser comparados com os de LENART \& PIOTROWSKI [15], que trabalharam com cubos de maçã e testaram diversos revestimentos colocados previamente à DO. O aumento de umidade do conjunto fruta/cobertura de pectina 3\% também foi observado pelos autores, mesmo com a secagem parcial do mesmo em estufa $\left(70^{\circ} \mathrm{C}\right.$ por 10 ou 40 minutos). Os autores não detectaram ganho significativo de massa seca devido à cobertura. Esta, formada com $3 \%$ de pectina, causou diminuição de perda de água e de ganho de sólidos, após 3 horas de DO em solução de sacarose $61,5 \%$, $(\mathrm{p} / \mathrm{p})$ em relação à fruta sem cobertura. Em um trabalho anterior, LENART \& DABROWSKA [14] observaram um aumento da eficiência na DO (sacarose $61,5 \% \mathrm{p} / \mathrm{p}, 30^{\circ} \mathrm{C}$ ) de cubos de maçã revestidos com coberturas de pectina $2 \%$, em comparação com a fruta sem revestimento, devido ao menor ganho de sólidos, que caiu $40 \%$ em $2 \mathrm{~h}$ de processo. Com temperatura elevada $\left(80^{\circ} \mathrm{C}\right)$, a eficiência do processo foi notavelmente aumentada, sendo que, em $2 \mathrm{~h}$, a saída de água foi $25 \%$ maior e o ganho de soluto $50 \%$ menor em relação à fruta sem revestimento. Isso ocorreu provavelmente porque, nesta temperatura, bastante elevada, o tecido celular perdeu suas propriedades de semi-permeabilidade e se encharcou de soluto. Temperaturas acima de $55^{\circ} \mathrm{C}$ causam danos irreversiveis nas membranas plasmáticas [26]. MAURO \& MENEGALLI [16] observaram que o soluto penetra em maior quantidade na fruta que é submetida a branqueamento a vapor, previamente à $\mathrm{DO}$, do que naquela que não é submetida ao mesmo. A concentração elevada da solução $(61,5 \%$ de sacarose) também pode causar alguma injúria às primeiras camadas de células do tecido vegetal. Técnicas de microscopia mostraram que soluções de $60 \%$ de sacarose causaram significativa injúria ao tecido celular de maçãs, viabilizando a entrada de soluto em todos os espaços da célula [22].

AZEREDO \& JARDINE [2] obtiveram aumento na eficiência da DO de abacaxis revestidos com alginato ou pectina de baixa metoxilação, em comparação com frutas sem cobertura. Possivelmente a temperatura do branqueamento causou alguma injúria ao tecido vegetal, que tornou-se mais permeável ao soluto. Além disso, as concentrações da solução osmótica eram altas, o que também poderia causar efeito nas células do tecido. Como resultado, o desempenho das coberturas mostrou-se bem mais eficiente que o tecido vegetal, quanto a aumentar a perda de água em relação ao ganho de soluto.

\section{3 - Comparação entre concentrações de $\mathrm{CaCl}_{2}$ adi- cionado às soluções osmóticas - Conjunto III}

Estudou-se a influência da adição de cloreto de cál- 
cio nas soluções osmóticas com $50 \%$ de sacarose. Os ensaios foram conduzidos em plataforma de agitação (item "Desidratação osmótica em plataforma de agitação (shaker)"). A espessura média das amostras foi $4,4 \mathrm{~mm}$. Foram determinados açúcares totais e redutores em todas as amostras, o que possibilitou estimar a variação de açúcares redutores nas fatias, durante o processo.

Na Tabela 7 são apresentados o teor final de umidade, a variação total de massa (equação 1), a perda de água (equação 2), o ganho de sacarose (equação 4) e a perda de açúcares redutores (equação 6), os quatro últimos em relação à massa inicial que foi imersa na solução osmótica, e a eficiência (equação 7).

TABELA 7 - Teor de umidade $\left(U_{t}\right)$, variação de massa $(\Delta M)$, perda de água $\left(\Delta P_{\star{ }_{\text {a }}}\right)$, ganho de sacarose $\left(\Delta G_{\ldots \ldots \ldots} \ldots\right)$, perda de açúcares redutores $\left(\Delta P_{\text {........ }}\right)$ e eficiência $(E)$ na DO de fatias de carambola em solução de sacarose $(50 \%)$, adicionada ou não de $\mathrm{CaCl}_{2}$

\begin{tabular}{ccccccc}
\hline $\begin{array}{c}\text { Concentração } \\
\text { de } \mathrm{CaCl}_{2}\end{array}$ & $\begin{array}{c}U, \\
(\%, \mathrm{bu})\end{array}$ & $\begin{array}{c}\Delta M \\
(\%)\end{array}$ & $\begin{array}{c}\Delta P_{\text {dswa }} \\
(\%)\end{array}$ & $\begin{array}{c}\Delta G_{\text {socanse }} \\
(\%)\end{array}$ & $\begin{array}{c}\Delta P_{\text {ox md }} \\
(\%)\end{array}$ & $E$ \\
\hline $0,06 \mathrm{M}$ & $69,38 \pm 0,04$ & $-56,71$ & $-60,84$ & 5,20 & $-1,31$ & $-11,70$ \\
$0,04 \mathrm{M}$ & $70,96 \pm 0,08$ & $-55,76$ & $-59,47$ & 4,25 & $-0,88$ & $-14,00$ \\
$0,02 \mathrm{M}$ & $71,43 \pm 0,19$ & $-52,24$ & $-56,47$ & 4,69 & $-0,44$ & $-12,04$ \\
0 & $73,83 \pm 0,08$ & $-49,79$ & $-53,52$ & 4,29 & $-0,54$ & $-12,48$ \\
\hline
\end{tabular}

Neste caso, a concentração de $0,04 \mathrm{M}$ de $\mathrm{CaCl}_{2}$ foi aquela que proporcionou maior eficiência (perda de água/ganho de sólidos) em relação aos outros tratamentos, apesar das diferenças terem sido pequenas entre os mesmos.

Na Tabela 8 são reportados os teores finais de sacarose e de açúcares redutores determinados experimentalmente (titulação de óxido-redução), em base úmida e em base seca.

TABELA 8 - Teor de sacarose $(S)$ e açúcares redutores $(A R)$ na DO de fatias de carambola em solução de sacarose (50\%), adicionada ou não de $\mathrm{CaCl}_{2}$

\begin{tabular}{ccccc}
\hline $\begin{array}{c}\text { Concentração } \\
\text { de } \mathrm{CaCl}_{2}\end{array}$ & $S_{,}(\%, \mathrm{bu})$ & $S_{,}(\%, \mathrm{bs})$ & $A R_{f}(\%, \mathrm{bu})$ & $A R_{f}(\%, \mathrm{bs})$ \\
\hline $0,06 \mathrm{M}$ & 13,55 & 44,25 & 10,69 & 34,91 \\
$0,04 \mathrm{M}$ & 11,12 & 38,29 & 11,44 & 39,39 \\
$0,02 \mathrm{M}$ & 11,21 & 39,24 & 11,52 & 40,32 \\
0 & 9,87 & 37,71 & 10,75 & 41,08 \\
\hline \multicolumn{5}{l}{ Teores médios (base úmida) na carambola in natura: água $90,73 \% ;$ açúcar redutor $5,94 \% ;$}
\end{tabular}

A utilização do cloreto de cálcio teve resultados positivos, porém, de significância moderada, apresentando um leve aumento na perda de água. No entanto, os resultados obtidos por HENG, GUILBERT \& CUQ [12], que desidrataram cubos de mamão em soluções de sacarose a $65^{\circ} \mathrm{Brix}, \mathrm{a} 60^{\circ} \mathrm{C}$, com adição de cloreto de cálcio em várias concentrações, mostram que a redução do ganho de sacarose em relação a soluções sem o cálcio foi grande para esse caso. Porém, além das diferenças inerentes aos tecidos, as condições de tratamento (concentração e tem- peratura da solução) utilizadas com a carambola foram mais moderadas que as utilizadas com mamão. Provavelmente, as condições mais drásticas provocaram grande impregnação de açúcar no mamão desidratado sem o cálcio, chegando a um ganho de 9,3\% de sólidos em 2 horas de processo.

Devido à maior eficiência, a desidratação osmótica em solução de sacarose a $50 \%$, com adição de $\mathrm{CaCl}_{2} \mathrm{em}$ concentração de $0,04 \mathrm{M}$, foi selecionada como prétratamento para a secagem das amostras a 60 e $70^{\circ} \mathrm{C}$, que foram submetidas a testes sensoriais de preferência.

\section{4 - Análise sensorial}

Aparência, textura e sabor foram avaliados sensorialmente em carambola em fatias, secas a 60 e $70^{\circ} \mathrm{C}$, sem tratamento osmótico, com tratamento osmótico em solução de sacarose $50 \%$ e após tratamento osmótico em solução de sacarose $50 \%$ com adição de $\mathrm{CaCl}_{2}$ a 0,04M. Os resultados obtidos foram tratados estatisticamente por análise de variância (ANOVA) fator duplo sem repetição e teste de Tukey [6] utilizando programa ExcelMicrosoft.

As médias das notas e desvios padrão obtidos pelas amostras com relação aos atributos aparência, textura e sabor são apresentadas na Figura 1 e resumidas na Tabela 9. Todos atributos das amostras obtiveram médias acima de 5 , sendo que, de um modo geral, as melhores notas foram atribuídas à aparência.

Para as duas temperaturas de secagem, as amostras

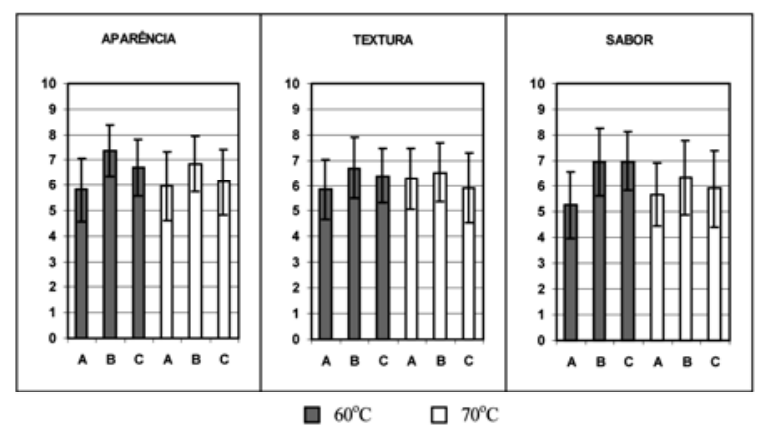

FIGURA 1 - Gráficos das médias e desvios padrão das notas de aparência, textura e sabor de carambolas em fatias secas a $60^{\circ} \mathrm{C}$ e $70^{\circ} \mathrm{C}$, sem pré-tratamento (A), pré-tratadas em solução de sacarose $50 \%$ (B) e em solução de sacarose $50 \%$ com adição de $\mathrm{CaCl}_{2}$ a $0,04 \mathrm{M}$ (C)

sem pré-tratamento apresentaram médias inferiores para aparência e sabor, quando comparadas com as amostras pré-tratadas, mostrando a influência do tratamento osmótico antes da secagem. Com relação à textura, no entanto, os pré-tratamentos parecem não ter afetado a avaliação.

Para o atributo sabor, as médias das amostras prétratadas foram maiores que as sem tratamento, sendo a 
Desidratação osmótica de carambolas, Shigematsu et al.

TABELA 9 - Valores médios para aparência, textura e sabor de carambolas em fatias secas a 60 e $70^{\circ} \mathrm{C}$, tratadas e não tratadas em soluções de sacarose com e sem adição de $\mathrm{CaCl}_{2}$

\begin{tabular}{|c|c|c|c|c|c|c|c|}
\hline \multirow{3}{*}{ Atributo } & \multirow{3}{*}{ DMS* } & \multicolumn{6}{|c|}{ Temperaturas de secagem e pré-tratamentos } \\
\hline & & \multicolumn{3}{|c|}{$60^{\circ} \mathrm{C}$} & \multicolumn{3}{|c|}{$70^{\circ} \mathrm{C}$} \\
\hline & & $\begin{array}{c}\text { sem } \\
\text { tratamento }\end{array}$ & sacarose & $\begin{array}{c}\text { sacarose } \\
+\mathrm{CaCl}_{2}\end{array}$ & $\begin{array}{c}\text { sem } \\
\text { tratamento }\end{array}$ & sacarose & $\begin{array}{c}\text { sacarose } \\
+\mathrm{CaCl}_{2}\end{array}$ \\
\hline Aparência & 1,4 & $5,9^{\mathrm{a}}$ & $7,4^{b}$ & $6,8^{\mathrm{ab}}$ & $6,0^{\mathrm{ab}}$ & $6,9^{a b}$ & $6,2^{\mathrm{ab}}$ \\
\hline Textura & 1,1 & $5,9^{a}$ & $6,7^{a}$ & $6,4^{\mathrm{a}}$ & $6,3^{\mathrm{a}}$ & $6,6^{a}$ & $6,0^{\mathrm{a}}$ \\
\hline Sabor & 1,2 & $5,4^{\mathrm{a}}$ & $7,0^{\mathrm{b}}$ & $7,0^{\mathrm{b}}$ & $5,8^{\mathrm{a}}$ & $6,4^{\text {ab }}$ & $6,0^{\text {ab }}$ \\
\hline Média & 0,9 & $5,7^{\mathrm{a}}$ & $7,0^{\mathrm{b}}$ & $6,7^{\mathrm{ab}}$ & $6,0^{\mathrm{ab}}$ & $6,6^{\mathrm{ab}}$ & $6,1^{\text {ab }}$ \\
\hline
\end{tabular}

diferença significativa para as amostras secas a $60^{\circ} \mathrm{C}$. A carambola é muito ácida ( $\mathrm{pH}$ em torno de 4,0), e quando desidratada osmoticamente, ganha açúcar da solução, o que pode melhorar o sabor da fruta por diminuir a percepção do gosto ácido. Além disso, a presença do cálcio poderia reduzir ligeiramente o $\mathrm{pH}$ da fruta, devido à formação de complexos com os ácidos orgânicos [21]. No entanto, as notas atribuídas ao sabor foram muito semelhantes entre as amostras com e sem a presença do cálcio, para cada temperatura testada.

Também parece não ter sido detectado o gosto amargo residual nas amostras tratadas em solução com $\mathrm{CaCl}_{2}$, como observado por HENG, GUILBERT \& CUQ [12] em mamão tratado osmoticamente em solução de sacarose com adição de $0,05 \mathrm{M}$ de Ca.

As amostras pré-tratadas foram melhor avaliadas quanto à aparência, provavelmente por apresentarem cor mais clara e brilhante que as amostras não tratadas, sugerindo que a solução osmótica exerceu uma proteção na superficie da fruta, minimizando o escurecimento enzimático. Segundo BALDINI, DRAETTA \& NOMURA [3] a peroxidase é a causa fundamental do escurecimento da carambola na presença de oxigênio, pois catalisa a oxidação de compostos fenólicos em presença de peróxido de hidrogênio. Há indícios de que a presença do cálcio também contribui para a manutenção da cor clara da carambola desidratada, por longos períodos de armazenamento. No entanto, testes durante o armazenamento terão que ser conduzidos para comprovação do mesmo.

\section{5 - Nomenclatura}

$\begin{array}{ll}\text { AR } & \text { teor de açúcares redutores [-] } \\ \text { bs } & \text { base seca } \\ \text { bu } & \text { base úmida } \\ \text { Ca } & \text { adição de cloreto de cálcio na solução osmótica } \\ \text { CB } & \text { adição de cobertura } \\ \text { CB-DO } & \begin{array}{l}\text { adição de cobertura seguida de desidratação } \\ \text { osmótica }\end{array} \\ \text { CB-S-DO adição de cobertura seguida de secagem par- } & \text { cial em estufa (40 C, } 40 \text { min, } 70 \text { C, } 10 \text { e } 40 \text { min) } \\ \text { e de desidratação osmótica } \\ \text { DO desidratação osmótica }\end{array}$

DO-Ca desidratação osmótica com adição de cálcio na solução

E $\quad$ eficiência (equação 7) [-]

$S \quad$ teor de sacarose [-]

t tempo [T]

$U$ teor de umidade [-]

$\Delta M \quad$ variação de massa em relação à massa inicial (equação 1) [-]

$\Delta P_{\text {s }, \text { a }} \quad$ perda de água em relação à massa inicial (equação 2) [-]

$\Delta G_{\text {sulu }}$ ganho de sólidos em relação à massa inicial (equação 3) [-]

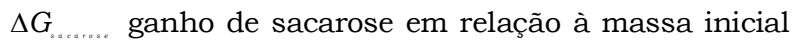
(equação 4) [-]

$\Delta P_{\text {s...... }} \quad$ perda de açúcares redutores em relação à massa inicial (equação 6) [-]

$\rho \quad$ densidade $\left[M / L^{3}\right]$

\section{Subindices}

$i \quad$ inicial

$f \quad$ final

c coberturas

$f / c \quad$ conjunto fatia/cobertura

\section{4 - CONCLUSÕES}

Para a condição moderada de DO (sacarose 50\%, $27^{\circ} \mathrm{C}, 2 \mathrm{~h}$ ) de fatias de carambola, a adição de coberturas à base de pectina diminuiu a eficiência do processo. $\mathrm{O}$ tecido vegetal sempre mostrou desempenho melhor quanto à restrição do ganho de solutos, em comparação com a fruta revestida com coberturas.

A adição de $\mathrm{CaCl}_{2}$ na própria solução osmótica em concentração de $0,04 \mathrm{M} \mathrm{de} \mathrm{CaCl}_{2}$, provocou um ligeiro aumento na eficiência da DO de fatias de carambola, quando comparada com a DO de fatias tratadas sem a presença do cálcio.

A DO, com e sem cloreto de cálcio na solução, contribuiu para a maior aceitação dos produtos desidratados com ar aquecido a $60^{\circ} \mathrm{C}$, em comparação com aqueles não tratados. 


\section{5 - REFERÊNCIAS BIBLIOGRÁFICAS}

[1] ARAÚJO, P.S.R. de; SCARPARE FILHO, J.A.; MINANI, K. Seleção de Caramboleiras pelas características biométricas e físico-química dos frutos. Scientia Agrícola, v. 58, n. 1, p. 91-99, 2001.

[2] AZEREDO, H.M.C.; JARDINE, J.G.. Desidratação osmótica de abacaxi aplicada à tecnologia de métodos combinados. Ciênc. Tecnol. Aliment., v. 20, n. 1, p. 7882, 2000.

[3] BALDINI, V.L.S.; DRAETTA, L. S.; NOMURA, E.H. Avaliação bioquímica da carambola (Averrhoa Carambola L.). Coletânea do Instituto de Tecnologia de Alimentos, v. 12, p. 283-291, 1982.

[4] BARRERA, C.; BETORET, N.; FITO, P. Ca2+ and Fe2+ influence on the osmotic dehydration kinetics of apple slices (var. Granny Smith). Journal of Food Engineering, v. 65, p. 9-14, 2004.

[5] BIDWELL, R.G.S. Plant Physiology. $2^{\text {nd }}$ edition. New York: Macmillan Publishing Co., Inc., 1979, 726p.

[6] BOX, G.E.P; HUNTER, W.G; HUNTER, J. S. Statistics for Experimenters: An Introduction to Design, Data Analysis, and Model Building. New York, John Wiley\& Sons, 1978. 653p.

[7] BRANDÃO, M.C.C.; MAIA, G.A.; LIMA, D.P.; PARENTE E.J. de S.; CAMPELLO, C.C.; NASSU, R.T.; FEITOSA, T.; SOUZA, P.H.M. Análise físico-química, microbiológica e sensorial de frutos de manga submetidos à desidratação osmótico-solar. Revista Brasileira de Fruticultura, v. 25, n. 1, p. 38-41, 2003.

[8] CAMIRAND, W.,M.; FORREY, R.R.; POPPER, K.; BOYLE, F.P; STANLEY, W.L. Dehydration of membrane-coated foods by osmosis. Journal of the Science of Food and Agriculture, v. 19, p. 472-474, 1968.

[9] CAMIRAND, W.M.; KROCHTA, J.M.; PAVLATH, A.E.; WONG, D.; COLE, M.E. Properties of some edible carbohydrate polymer coatings for potential use in osmotic dehydration. Carbohydrate Polymers, v. 17, n. 1, p. 39-49, 1992.

[10] DONHOWE, I.G.; FENNEMA, O. Edible films and coatings: characteristics, formation, definitions, and testing methods. In: Krochta, J. M., Baldwin, E. A., Nisperos-Carriedo, M. O. (Ed.). Edible Coatings and Films to Improve Food Quality. Lancaster, Technomic. p.1-24, 1994.

[11] GIANGIACOMO, R.; TORREgGiani, D.; ABBO E. Osmotic dehydration of fruit. Part I. Sugars exchange between fruit and extracting syrups. Journal of Food Processing and Preservation, v.11, n. 9, p. 183-195, 1987.

[12] HENG, H.; GUILBERT, S.; CUQ, J. L. Osmotic dehydration of papaya: influence of process variables on the product quality. Sciences des Aliments, v. 10, p. 831-848, 1990.

[13] ISHIKAWA, M.; HIDETOSHI, N. Inhibition of solute permeation in osmotic dehydration of food by chitosan membrane coating. Nippon Suisan Gakkaishi, v. 57, n. 4, p. 767, 1990.

[14] LENART, A.; DABROWSKA, R. Kinetics of osmotic dehydration of a apples with pectin coatings. Drying Technology, v. 17, n. 78, p. 1359-1373, 1999.

[15] LENART, A.; PIOTROWSKI, D. Drying characteristics of osmotically dehydrated fruits coated with semipermeable edible films. Drying Technology, v. 19, n. 5, p. 849-877, 2001.

[16] MAURO, M.A.; MENEGALLI, F.C. Evaluation of diffusion coefficients in osmotic concentration of bananas (Musa Cavendish Lambert). International of Food Science and Technology, v. 30, p. 199-213, 1995.

[17] MURARI, R. de C.B.D.L. Cinética da Desidratação Osmo-convectiva de tomates. São José do Rio Preto, 2000, Dissertação (Mestre em Engenharia de Alimentos), Universidade Estadual Paulista (UNESP).

[18] NOBEL, P.S. Physicochemical and Environmental Plant Physiology. San Diego: Academic Press, Inc. 1991, 635p.

[19] OGONEK, A.; LENART A. Influence of selective edible coatings on osmotic dehydration of strawberries. FSTA, Food Science and Technology Abstracts, (08):J1885, 2002.

[20] PRATI, P.; NOGUEIRA, J.N.; DIAS, C.T.S. Avaliação de carambola (Averrhoa carambola L.) dos tipos doce e ácido para o processamento de fruta em calda. Boletim do Centro de Pesquisa e Processamento de Alimentos. v. 20, n. 2, p. 221-246, 2002.

[21] QUINTERO-RAMOS, A.; BOURNE, M.; BARNARD, R.; GONZÁLEZ-LAREDO, A.; ANZALDÚA-MORALES, M.; PENSABEN-ESQUIVEL; MÁRQUEZ-MELÉNDEZ, R. Low temperature blanching of frozen carrots with calcium chloride solutions at different holding times on texture of frozen carrots. Journal of Food Processing and Preservation. v.26, p. 361-374, 2002.

[22] RODRIGUES, A. E. Desidratação Osmótica e Secagem de Maçãs I. Comportamento do Tecido em Soluções Osmóticas II. Modelagem Matemática da Difusão, São José do Rio Preto, 2003, 122p. Dissertação (Mestre em Engenharia de Alimentos), Departamento de Engenharia e Tecnologia de Alimentos, Instituto de Biociências, Letras e Ciências Exatas (IBILCE), Universidade Estadual Paulista (UNESP).

[23] SÃO PAULO (Estado). CATI COORDENADORIA DE ASSISTÊNCIA TÉCNICA E INTEGRAL. Departamento de Sementes, Mudas e Matrizes (DSMM). Disponivel em $<$ http:// www.dsmm.cati.sp.gov.br>. Acesso em: maio 2005.

[24] SAUCO, V.G. Possibilities of non-citrus tropical fruit in the Mediterranean. Acta Horticulturae, n. 365, p. 2541, 1994.

[25] TEIXEIRA, G.H. de A.; DURIGAN, J.F.; DONADIO, L.C.; SILVA, J.A.A. da. Caracterização pós-colheita de seis cultivares de carambola (Averrhoa carambola L.). Revista Brasileira de Fruticultura, v. 23, n. 3, p. 546-550, 2001.

[26] THEBUD, R.; SANTARIUS, K.A. Effects of hightemperature stress on various biomembranes of leaf cells in situ and in vitro. Plant Physiology, v. 70, p. 200-205, 1982.

[27] TORRINGA, H.M.; ERLE, U.; BARTELS, P.V.; SCHUBERT, H. Microwave-vacuum drying of osmotically 
pre-treated fruit. In: DRYING '98 - PROCEEDINGS OF THE 11 TH INTERNATIONAL DRYING SYMPOSIUM (IDS '98).1998, Halkidiki, Greece, August 19-22, v. A, p. 922929.

[28] VIAL, C.; GUILBERT, S.; CUQ, J.L. Osmotic dehydration of kiwi fruits: influence of process variables on the color and ascorbic acid content. Sciences des Aliments. v. 11, p. 63-84, 1991.

[29] WILliAM, H. Official Methods of Analysis, 11th edition., Washington D.C.: Association of Official Analytical Chemists, Inc, 1970.

\section{6 - AGRADECIMENTOS}

Os autores agradecem à FUNDUNESP (Fundação para o Desenvolvimento da UNESP, Proc. 00003/03-DFP) pelo suporte financeiro, ao CNPq (Conselho Nacional de Desenvolvimento Científico e Tecnológico) e à FAPESP (Fundação de Amparo à Pesquisa do Estado de São Paulo, Proc. 03/09572-5) pela concessão de bolsa de mestrado e de iniciação científica, respectivamente, e à empresa Danisco pelo fornecimento de pectina. 